\title{
Differences in Anthropometric Characteristics between Athletes of Different Orientation, Handball and Volleyball
}

\author{
Marina Vukotic ${ }^{1}$, Georgi Georgijev ${ }^{2}$ \\ ${ }^{1}$ University of Montenegro, Faculty for Sport and Physical Education, Niksic, Montenegro, ${ }^{2}$ Ss. Cyril and Methodius University, Faculty for Physical \\ Education, Sport and Health, Skopje, North Macedonia
}

\begin{abstract}
The main goal of this research is to determine whether there are statistically significant differences in the level of anthropometric indicators among athletes of different sports directions (handball and volleyball players), that is, to determine the differences in the changes in the anthropometric indicators of athletes. The study was conducted on a sample of 50 subjects, a male gender divided into two subsample, 25 handball players and 25 volleyball players aged 13-15. In this study, 12 anthropometric variables were tested: body height, arm length, leg length, knee diameter, bicrystalline range, bichromium range, body mass, median volume of the thorax, circumference, upper abdomen, skin abdomen and skin set of lower legs. For all applied variables, the central and dispersion parameters as well as measures of asymmetry and flattening were calculated, and the distribution normality was verified by Kolmogorov-Smirnov test. T-test was applied to verify that the system of applied variables has statistically quantitative differences between groups. On the basis of the obtained results, it can be concluded that there are statistically significant differences in anthropometric indicators in athletes of different sports orientations. This research can be used by trainers who realize training programs with these and other athletes in order to achieve better results.
\end{abstract}

Key words: Handball, Volleyball, Anthropometric Characteristics, Montenegro

\section{Uvod}

Sport je fizička aktivnost, izvedena u okviru javno određenih pravila i običaja, koja se najčešće bavi takmičenjem, ali služi i za druge namjene: razonodu, razvijanje karakteristika, očuvanje zdravlja ili kombinaciju ovih elemenata (Bjelica, 2002). Najšire gledano, pod sportom se podrazumijeva specifična ljudska aktivnost koja ima za cilj sportski rezultat (Bjelica, 2006a). Smatra se da je jedan od osnovnih motiva koji pokreće ljude da se bave sportom upravo težnja za usavršavanjem i mjerenjem svojih sposobnosti i karakteristika, koje se mogu razvijati pod uticajem trenažnog procesa (Bjelica, 2005). Zadovoljenje sportskih potreba i interesa značajno je sa aspekta zdravlja, svestranog razvoja ličnosti sportiste, podizanja radne sposobnosti do nivoa sportske forme, te sposobnosti za učešće u sistemu takmičenja (Bjelica, 2006b). Sport u savremenim uslovima života predstavlja složen sistem različitih ak- tivnosti i oblika organizovanja kroz koje se ispoljavaju brojne i različite potrebe i interesi sportista (Bjelica, 2013; Popovic, 2017; Vukotic, Corluka, Vasiljevic, i Bubanja, 2018). Pošto je poznato da rezultat koji postižu sportisti u velikoj mjeri zavisi od morfoloških karakteristika (Masanovic, 2018; Masanovic, 2019; Vukasevic, Vukotic, i Masanovic, 2018; Vukotic i Georgiev, 2019a), bolje upoznavanje morfoloških karakteristika i konstitucije sportista ima za cilj: upravljanje ovim svojstvima i prilagođavanje sportskog treninga individualnim sposobnostima (Masanovic, Vukotic, Popovic, i Bjelica, 2018; Masanović, Vukotic, i Vukasevic, 2018; Vukotic i Georgiev, 2019b).

Rukomet i odbojka, kao sportske igre, zahtijevaju različite prethodno navedene dimenzije, a takođe i procese sportskog treninga i obučavanja (Vukotic, 2011; Masanovic, Milosevic, i Corluka, 2018; Masanovic, Corluka, i Milosevic, 2018; Vukotic, 2018). Jedan od neophodnih uslova za postizanje uspeha u

\section{Montenegro}

Gport

\section{Correspondence:}

\section{Vukotic}

University of Montenegro, Faculty for Sport and Physical Education, Narodne omladine bb, 81400 Niksic, Montenegro

E-mail:marinavuk@ucg.ac.me 
rukometu i odbojci je i talenat, jer sportisti koji posjeduju visok potencijal lakše i brže napreduju nego sportisti sa manjim nivoom potencijala, te se nameće zaključak da je rana identifikacija i selekcija talenta veoma važna karika na putu do uspjeha (Bjelica, 2004). Ako se uzme u obzir da je potrebno barem pet godina napornog treninga, i da je relativno mali vremenski period kada sportista može očekivati vrhunski učinak, postaje jasno da je veoma važno da se sportski potencijal otkrije što ranije i kontinuirano prati kako bi omogućio dovođenje do vrhunskog rezultata (Bompa, 2000). Za sportske trenere je od posebnog značaja da poznaju zakonitosti rasta i razvoja antropometrijskih karakteristika, motoričkih i funkcionalnih sposobnosti da bi primjena različitih treninga bila što efikasnija (Bjelica, Popovic, i Gardasevic, 2016a; Bjelica, Popovic, i Gardasevic, 2016b; Bjelica, Popović, Kezunovic, Petkovic, Jurak, i Grasgruber, 2012; Masanovic, Vukotic, Bjelica, i Popovic, 2018; Popovic, Bjelica, Vukotic, i Masanovic, 2018).

Antropometrijske karakteristike su veoma značajne za uspjeh u sporskim igrama kao što su rukomet i odbojka. U prostoru morfoloških dimenzija rukometaša i odbojkaša definisani su posebni faktori označeni kao latentne morfološke dimenzije: longitudinalna dimenzionalnost skeleta, transverzalna dimenzionalnost skeleta, masa i volumen tela i potkožno masno tkivo (Bjelica i Fratric, 2011). Morfološki status vrhunskih sportista su relativno homogeni, u zavisnosti od sporta, i mogu biti definisani kao modeli sportskog postignuća (Misigoj-Durakovic, Matkovic, i Medved, 1995). Sve više rukometaši pokazuju snažnu i obimnu muskulaturu gornjeg dijela tijela, što rezultira jačem i bržem šutu. Visina daje prednost u rukometu, jer ona igračima omogućava da lakše dođu do dobre pozicije za šut u napadu, odnosno lakše blokiraju protivnički napad (Arifi, Bjelica, i Masanovic, 2019). Prema igračkim mjestima najviši su spoljni igrači i golman, a najniži su krilni igrači (Vukotic, 2010). Većina elemenata naročito onih sa loptom su veoma složeni i specifični. Za njihovo usvajanje i besprekornu primjenu u igri potreban je visok nivo razvijenosti cjelokupnog motornog aparata (Vukasevic, Vukotic, i Masanovic, 2018). Savremenu odbojku, karakteriše dinamička, vrlo brza igra, sa mnogo eksplozivnih pokreta, skokova, preciznog odbijanja lopte, snažnog i preciznog servisa, smeča u utakmicama koje mogu trajati vrlo dugo. Da bi jedna vrhunska odbojkaška ekipa mogla da odgovori svim ovim zahtjevima, mora da ima visok nivo razvijenosti navedenih sposobnosti i karakteristika u kojima osnovu čine određene motoričke i funkcionalne sposobnosti kao i antropološke karakteristike (Vukotic, 2010).
Osnovni cilj ovog istraživanja je da se utvrdi da li postoje statistički značajne razlike u nivou antropometrijskih karakteristika između sportista različitog sportskog usmjerenja (rukomet i odbojka), odnosno da se preciznije ukaže na to kolike su ove razlike i gdje su najviše.

\section{Metod}

Uzorak ovog istraživanja čini 50 ispitanika, muškog pola podijeljenih na dva subuzorka. Prvi subuzorak čini 25 dječaka članova Rukometnog kluba „Sutjeska“, iz Nikšića, prosječnog uzrasta $13.73 \pm 6.18$, dok drugi subuzorak su čini 25 dječaka članova Odbojkaškog kluba „Volley star“, iz Nišića, prosječnog uzrasta $14.05 \pm 7.15$ godina.

Antropometrijsko istraživanje sprovedeno je uz poštovanje osnovnih pravila i principa vezanih za izbor mjernih instrumenata i tehnike mjerenja koji su standardizovani, prema upustvima Internacionalnog Biološkog Programa. Odabrane varijable u ovom istraživanju hipotetski pokrivaju prostor antropometrijskih karakteristika (12) i to: visina tijela, dužina ruke, dužina noge, dijametar koljena, bikristalni raspon, biakromijalni raspon, masa tijela, srednji obim grudnog koša, obim natkoljenice, kožni nabor nadlaktice, kožni nabor trbuha i kožni nabor potkoljenice.

Podaci dobijeni ovim istraživanjem obrađeni su postupcima deskriptivne i komparativne statističke procedure. Za sve primijenjene varijable izračunati su centralni i disperzioni parametri kao i mjere asimetrije i spljoštenosti, a normalnost distribucije provjerena je Kolmogorov-Smirnovljevim testom. Razlike u antropomerijskim karakteristikama između dvije grupe ispitanika (rukometaša i odbojkaša) utvrđene su primjenom diskriminativne parametrijske procedure, t-testom za male nezavisne uzorke, sa statističkom značajnošću od $p<0.05$.

\section{Rezultati}

U Tabelama 1 i 2 prikazani su osnovni deskriptivni statistički parametri antropometrijskih varijabli rukometaša i odbojkaša kadetskog uzrasta, gdje su izračunate vrijednosti mjera centralne i disperzione tendencije i to: aritmetička sredina, standardna devijacija, minimalne vrijednosti, maksimalne vrijednosti, koeficijent zakrivljenosti, koeficijent izduženosti i Kolmogorov-Smirnovljev test. Prvo su analizirani centralni i disperzioni parametri varijabli za procjenu antropometrijskih karakteristika rukometaša kadeta (Tabela 1 ).

Tabela 1. Centralni i disperzioni parametri varijabli za procjenu antropometrijskih karakteristika rukometaša kadetskog uzrasta $(\mathrm{N}=25)$

\begin{tabular}{lccccccc}
\hline & Mean & SD & Min & Max & Skew. & Kurt. & KS \\
\hline Visina tijela & 167.08 & 8.47 & 154.00 & 186.00 & 0.29 & -0.69 & 0.82 \\
Dužina ruke & 70.76 & 4.99 & 61.00 & 80.00 & -0.22 & -0.64 & 0.87 \\
Dužina noge & 89.58 & 7.40 & 78.50 & 104.00 & 0.02 & -0.93 & 0.88 \\
Dijametar koljena & 8.88 & 0.52 & 8.00 & 10.00 & 0.66 & 0.12 & 0.26 \\
Bikristalni raspon & 35.06 & 2.48 & 31.00 & 41.00 & 0.60 & 0.40 & 0.91 \\
Biakramijalni raspon & 37.39 & 2.73 & 33.00 & 46.50 & 1.49 & 4.16 & 0.57 \\
Masa tijela & 57.28 & 8.71 & 45.00 & 90.00 & 2.05 & 7.94 & 0.08 \\
Srednji obim grudnog koša & 80.42 & 5.40 & 71.00 & 95.50 & 0.67 & 1.13 & 0.91 \\
Obim natkoljenice & 41.23 & 3.93 & 34.00 & 50.50 & 0.54 & 0.26 & 0.60 \\
Kožni nabor nadlaktice & 11.36 & 2.01 & 6.67 & 15.30 & -0.28 & -0.14 & 0.55 \\
Kožni nabor trbuha & 10.51 & 2.84 & 5.67 & 15.67 & 0.04 & -0.65 & 1.00 \\
Kožni nabor potkoljenice & 11.15 & 3.11 & 3.67 & 19.67 & 0.64 & 2.49 & 0.31 \\
\hline
\end{tabular}

Legenda: Mean - aritmetička sredina; SD - standardna devijacija; Min - minimalni rezultat; Max - maksimalni rezultat; Skew. - koeficijent zakrivljenosti; Kurt. - koeficijent izduženosti i KS - Kolmogorov-Smirnov test 
Inspekcijom tabele uočljivo je da su dobijeni rezultati normalno distribuirani (prema K-S testu). Na osnovu centralnih i disperzionih parametara, vrijednosti skjunisa i kurtozisa,može se konstatovati da su sve varijable u granicama normalne raspodjele. Vrijednosti skjunisa kod varijabli sa pozitivnim predznakom, govore da su vrijednosti većine ispitanika u zoni slabijih vrijednosti i one su normalno asimetrične ili umjereno asimetrične, dok u mjerama dužina ruke i kožni nabor nadlaktice, koje su sa negativnim predznakom, govore da se vrijednosti većine ispitanika u zoni boljih rezultata. Negativne vrijednosti kurtozisa kod varijabli pokazuju veću spljoštenost (nagnutost) od normalnog oblika, tj. platikurtičnost. To ukazuje na heterogenost dobijenih rezultata, odnosno izraženiju diskriminativnost među ispitanicima. U mjeri masa tijela (Kurt=7.94) možemo konstatovati da su rukometaši najhomogeniji (leptokurtičnost).

Tabela 2. Centralni i disperzioni parametri varijabli za procjenu antropometrijskih karakteristika odbojkaša kadeta $(\mathrm{N}=25)$

\begin{tabular}{lccccccc}
\hline & Mean & SD & Min & Max & Skew. & Kurt. & KS \\
\hline Visina tijela & 178.58 & 8.13 & 161.00 & 190.00 & 0.22 & -0.85 & 0.92 \\
Dužina ruke & 76.54 & 3.47 & 70.00 & 85.00 & 0.49 & 0.41 & 0.53 \\
Dužina noge & 98.16 & 5.17 & 88.00 & 109.00 & 0.04 & -0.20 & 0.81 \\
Dijametar koljena & 8.85 & 0.60 & 7.80 & 10.00 & 0.26 & -0.74 & 0.96 \\
Bikristalni raspon & 35.02 & 2.02 & 31.00 & 39.00 & -0.44 & 0.08 & 0.20 \\
Biakramijalni raspon & 38.72 & 2.85 & 33.00 & 45.00 & 0.09 & 0.25 & 0.39 \\
Masa tijela & 66.28 & 10.60 & 35.00 & 80.00 & -0.12 & 0.05 & 0.90 \\
Srednji obim grudnog koša & 80.20 & 5.44 & 70.00 & 94.00 & 0.21 & 0.71 & 0.98 \\
Obim natkoljenice & 42.84 & 3.68 & 34.00 & 52.00 & -0.08 & 1.34 & 0.47 \\
Kožni nabor nadlaktice & 10.83 & 2.88 & 6.00 & 16.67 & 0.18 & -0.69 & 0.98 \\
Kožni nabor trbuha & 8.48 & 3.44 & 4.00 & 18.30 & 1.29 & 1.55 & 0.28 \\
Kožni nabor potkoljenice & 7.85 & 2.51 & 2.67 & 11.70 & -0.64 & -0.23 & 0.32 \\
\hline
\end{tabular}

$\mathrm{Na}$ osnovu dobijenih rezultata utvrđeno je da su rezultati normalno distribuirani (prema K-S testu). Na osnovu centralnih i disperzionih parametara, vrijednosti skjunisa i kurtozisa, može se konstatovati da su sve varijable u granicama normalne raspodjele. Vrijednosti skjunisa kod varijabli sa pozitivnim predznakom, govore da su vrijednosti većine ispitanika u zoni slabijih vrijednosti i one su normalno asimetrične ili umjereno asimetrične, dok su u mjeri kožni nabor trbuha sa odgovara- jućim vrijednostima 1,29 izraženo asimetrični i u zoni slabijih rezultata. Negativne vrijednosti kurtozisa kod varijabli pokazuju veću spljoštenost (nagnutost) od normalnog oblika, tj. leptokurtičnost. To ukazuje na heterogenost dobijenih rezultata, odnosno izraženiju diskriminativnost među ispitanicima. Da bi se moglo utvrditi da li ima statistički značajnih razlika u analiziranim varijablama kod rukometaša i odbojkaša kadetskog uzrasta, primijenjena je statistička procedura t-test (Tabela 3).

Tabela 3. Razlika izmedju aritmetičkih sredina varijabli za procjenu antropometrijskih karakteristika kadeta rukometaša ( $\mathrm{N}=25)$ i kadeta odbojkaša $(\mathrm{N}=25)$

\begin{tabular}{lccccc}
\hline Varijabla & Grupe & Mean & SD & t & Sig \\
\hline Visina tijela & Rukometaši & 167.08 & 8.47 & 2.34 & $.030^{*}$ \\
Dužina ruke & Odbojkaši & 178.58 & 8.13 & & \\
Dužina noge & Rukometaši & 70.76 & 4.99 & 3.11 & $.000^{*}$ \\
Odbojkaši & 76.54 & 3.47 & & \\
Dijametr koljena & Rukometaši & 89.58 & 7.40 & 2,51 & $.023^{*}$ \\
Bikristalni raspon & Odbojkaši & 98.16 & 5.17 & & \\
& Rukometaši & 8.88 & 0.52 & -1.05 & .070 \\
Biakramijalni raspon & Odbojkaši & 8.85 & 0.60 & & \\
Masa tijela & Rukometaši & 35.06 & 2.48 & 3.69 & .105 \\
Srednji obim grudnog koša & Odbojkaši & 35.02 & 2.02 & & \\
Obim natkoljenice & Rukometaši & 37.39 & 3.15 & 1.98 & .126 \\
& Odbojkaši & 38.72 & 2.73 & & \\
Kožni nabor nadlaktice & Rukometaši & 57.28 & 10.34 & 2.99 & $.012^{*}$ \\
Kožni nabor trbuha & Odbojkaši & 56.28 & 10.60 & & \\
Kožni nabor potkoljenice & Rukometaši & 80.42 & 5.40 & 3.19 & .184 \\
& Odbojkaši & 80.20 & 5.44 & & \\
\hline & Rukometaši & 41.23 & 3.39 & 3.15 & $.013^{*}$ \\
& Odbojkaši & 42.84 & 3.68 & & \\
& Rukometaši & 11.36 & 2.18 & 1.50 & .177
\end{tabular}

Legenda: Mean - aritmetička sredina; SD - standardna devijacija; t - vrijednosti t testa i Sig. - značajnost razlike; * - značajna razlika između grupa 
Na osnovu rezultata se može vidjeti da razlike postoje, što nam potvrđuju i vrijednosti T- testa sa statističkom značajnošću na nivou $\mathrm{p}<0.05$. Prilikom utvrđivanja razlika kod antropometrijskih parametara, očigledna je statistička značajnost kod sljedećih varijabli: visine tijela, dužina ruke, dužina noge, mase tijela, obim natkoljenice, kožni nabor trbuha i kožni nabor potkoljenice, dok statistička razlika ne postoji kod varijabli: dijametar koljena, bikristalni raspon, biakromijalni raspon, srednji obim grudnog koša i kožni nabor nadlaktice.

\section{Diskusija}

$\mathrm{Na}$ osnovu dobijenih deskriptivnih parametara ovog istraživanja prosječna tjelesna visina rukometaša je $167.08 \mathrm{~cm}$, a masa tijela rukometaša je $57.28 \mathrm{~kg}$, što pokazuje da oni imaju veoma slične vrijednosti sa igračima iz Hrvatske koji su istog uzrasta (Ostroski, Milanovic, i Metikos, 2014) gdje je prosječna tjelesna visina rukometaša bila $167.00 \mathrm{~cm}$ a masa tijela je iznosila $62.70 \mathrm{~kg}$. Opšti zaključak je da postoji sličnost naših i hrvatskih igrača i to ohrabruje, jer hrvatski rukometaši su godinama u svjetskom vrhu, što može da znači da smo na dobrom putu da se i mi tamo nađemo. Posljednjih godina se u rukomet puno ulaže o čemu govore i rezultati muške kadetske reprezentacije Crne Gore koja je osvojila srebrnu medalju na Mediteranskom prvenstvu u Egiptu 2019. godine. Seniorska reprezentacija uspjela je da se plasirala na evropsko prvenstvo, jer su u kvalifikacijama pobjeđivali najjače evropske ekipe među kojima i aktuelnog osvajača zlatne olimpijske medalje i aktuelnog svjetskog prvaka Dansku.

$\mathrm{Na}$ osnovu dobijenih deskriptivnih parametara ovog istraživanja prosječna tjelesna visina odbojkaša je $178.58 \mathrm{~cm}$, a masa tijela odbojkaša je $66.28 \mathrm{~kg}$, pa vidimo da oni imaju nešto niže vrijednosti u odnosu na reprezentativce Srbije istog uzrasta (Bogdanovic et al., 2014) gdje je prosječna tjelesna visina bila $181.87 \mathrm{~cm}$ a masa tijela je iznosila $70.53 \mathrm{~kg}$. Možda je to osnovni razlog zašto crnogorski odbojkaši nijesu uspješni na međunarodnim takmičenjima kao srbijanski odbojkaši sa kojima je vršeno poređenje. Na osnovu navedenog odbojkaški stručnjaci bi trebalo da više vode računa o selekciji jer imaju populaciju koja je veoma visoka (Bjelica, i sar. 2016a; Masanovic, 2017; Vukotic, 2018, Masanovic, 2018b).

Može se zaključiti da kod primijenjenog sistema antropometrijskih mjera postoje statistički značajne razlike između rukometaša i odbojkaša, što se vidi na osnovu rezultata T-testa za male nezavisne uzorke. Dobijeni rezultati dijelom potvrđuju važnost longitudinalne dimenzionalnosti skeleta u razlikovanju selekcionisanih rukometaša i odbojkaša kadetskog uzrasta (Cselko, Laszlo, Tekus, i Wilhelm, 2013; Katic, Grgantov, i Jurko, 2006), jer razlike ukazuju da su za uspješnost u igri kod mladih rukometaša i odbojkaša potrebne različite morfološke karakteristike (Vukotic, 2010). U sportskoj praksi dobro je poznat problem prerane specijalizacije kao i neuvažavanja fiziološke zrelosti u procjeni krajnjih mogućnosti mladih sportista (Masanovic, Popovic, i Bjelica, 2018) što može dovesti na krivi put. Korisnije je da se sve u cilju postizanja vrhunskih rezultata, pokuša pronaći adekvatan somatotip za određene sportove, nivoe takmičenja i igračke pozicije (Massuça, i Fragoso, 2011).

Rezultati koji su dobijeni ovim istraživanjem mogu poslužiti kao modelni parametri u procjenjivanim varijablama za sve ostale igrače istog ranga takmičenja u Crnoj Gori, kao i za upoređivanje sa rezultatima dobijenim u drugim, sličnim istraživanjima. Treba napomenuti da igrači koje žele uspješno nastupati u ligama gdje se igra najkvalitetniji rukomet i odbojka, moraju imati karakteristike utvrđene standardima za taj sport, a to se prije svega ogleda $u$ antropometrijskim karakteristikama. Jer prilikom selekcije bitno je dati prednost onim igračima koji svojim antropometrijskim karakteristikama zadovoljavaju zahtjeve prema igračkim pozicijama u navedenim sportskim igrama (Gabbett i Georgieff, 2007), a ostale bi trebalo usmjeriti ka sportovima gdje prema svojim morfološkim karakteristikama mogu imati više uspjeha jer veliki je broj vrhunskih sportista koji su čak i u ovim godinama promijenili sport pa vrhunske uspjehe postigli u sportu koji nije bio njihov prvi izbor.

\section{Acknowledgements}

There are no acknowledgements.

\section{Conflict of Interest}

The authors declare that there are no conflicts of interest.

Received: 10 June 2019| Accepted: 29 July 2019| Published: 11 October 2019

\section{References}

Arifi, F., Bjelica, D., \& Masanovic, B. (2019). Differences in anthropometric characteristics among junior soccer and handball players. Sport Mont, 17(1), 45-49. doi: $10.26773 /$ smj. 190208

Bjelica, D. (2002). Opšti pojmovi sportskog treninga: (skraćena verzija). Podgorica: Crnogorska sportska akademija.

Bjelica, D. (2004). Uticaj sportskog treninga na antropomotoričke sposobnosti: (fudbalskih kadeta Crne Gore). Podgorica: Crnogorska sportska akademija.

Bjelica, D. (2005). Sistematizacija sportskih disciplina i sportski trening. Podgorica: Crnogorska sportska akademija.

Bjelica, D. (2006a). Sportski trening. Podgorica: Crnogorska sportska akademija. Bjelica, D. (2006b). Teorijske osnove tjelesnog i zdrastvenog obrazovanja. Podgorica: Crnogorska sportska akademija.

Bjelica, D. (2013). Teorija sportskog treninga. Podgorica: Univerzitet Crne Gore.

Bjelica, D., \& Fratric, F. (2011). Sportski trening: teorija, metodika i dijagnostika. Nikšić: Fakultet za sport i fizičko vaspitanje.

Bjelica, D., Popović, S., i Gardašević, J. (2016a). Modeli fizičke pripreme vrhunskih sportaša i doziranje opterećenja. Zbornik radova 14. godišnje međunarodne konferencije "Kondicijska priprema sportaša" (185-189), Zagreb: Udruga kondicijskih trenera Hrvatske.

Bjelica, D., Popović, S., i Gardašević, J. (2016b). Opći principi planiranja i programiranja fizičkih priprema sportaša. Zbornik radova 14. godišnje međunarodne konferencije "Kondicijska priprema sportaša" (190-192), Zagreb: Udruga kondicijskih trenera Hrvatske.

Bogdanovic, Z., Smajic, M., Jaksic, D., Obradovic, M., Gogic, A., Vidakovic, H.M., Ljubisavljevic, M., Draskovic, V., Visnjic, S., Mekic, H., Stankovic, R., Ivancic, G., \& Popovic, S. (2014). Lumbar and abdominal muscles isometric potential in volleyball cadets. International Journal of Morphology, 32(3), 10361042.

Bompa T. (2000). Periodizacija: Teorija i metodika treninga. Zagreb: Hrvatski košarkaški savez.

Cselko, A., Laszlo, Z., Tekus, E., \& Wilhelm, M. (2013). Morphological, motor and situation-motor characteristics of elite female handball players according to playing performance and position. Collegium Antropologicum 34(4),1355-61.

Gabbett, T. \& Georgieff, B. (2007). Physiological and anthropometric characteristics of Australian junior national, state, and novice volleyball players. Journal of Strength and Conditioning Research, 21(3), 902-8.

Gaurav, V., Singh, M., \& Singh, S. (2010). Anthropometric characteristics, somatotyping and body composition of volleyball and basketball players. Journal of Physical Education and Sports Management, 1(3), 28-32.

Masanovic, B. (2018). Comparative study of anthropometric measurement and body composition between junior basketball and volleyball players from Serbian national league. Sport Mont, 16(3), 19-24. doi: 10.26773/smj.181004

Masanovic, B. (2019). Comparative Study of Morphological Characteristics and Body Composition between Different Team Players from Serbian Junior National League: Soccer, Handball, Basketball and Volleyball. International Journal of Morphology, 37(2), 612-619.

Masanovic, B., Corluka, M., \& Milosevic, Z. (2018). Comparative Study of Anthropometric Measurement and Body Composition of Junior Soccer and Handball Players from the Serbian National League. Kinesiologia Slovenica 24(3), 37-46.

Masanovic, B., Milosevic, Z., \& Corluka, M. (2018). Comparative Study of Anthropometric Measurement and Body Composition between Junior Handball and Volleyball Players from Serbian National League. International Journal of Applied Exercise Physiology, 7(4), 1-6. https://doi.org/10.30472/ijaep. v7i4.313 
Masanovic, B., Vukotic, M., \& Vukasevic, V. (2018). Comparative study of morphological characteristics and body composition between elite basketball players from different regions. Journal of Anthropology of Sport and Physical Education, 2(4), 103-107. doi: 10.26773/jaspe.181019

Masanovic, B., Vukotic, M., Popovic, S., \& Bjelica, D. (2018). Comparative study of anthropometric measurement and body composition between junior basketball and volleyball players from Serbian national league. World Congress of Performance Analysis of Sport XII (340). Croatia: University of Zagreb.

Massuca, L., \& Fragoso, I. (2011). Study of Portuguese handball players of diff erent playing status. A morphological and biosocial perspective. Biology of Sport, 28(1), 37-44.

Misigoj-Durakovic, M., Matkovic, B., \& Medved, R. (1995). Morfološka antropometrija u športu. Morphological anthropometry in sports. Zagreb, Croatia: Fakultet za fizičku kulturu.

Ostroski, S., Milanovic, M., i Metikos, B. (2014). Razlike nogometaša i rukometaša dobi 13 do 14 godina uključenih u školski sportski klub u nekim kondicionim obilježima. U zborniku radova 23 Ljetnje škole ki-neziologa Republike Hrvatske (231-236), Zagreb: Hrvatski kineziološki savez.

Popovic, S. (2017). Local Geographical Differences in Adult Body Height in Montenegro. Montenegrin Journal of Sports Science and Medicine, 6(1), 8187.

Popovic, S., Bjelica, D., Vukotic, M., \& Masanovic, B. (2018). Describing Physical Activity Profile of Older Montenegrin Females Using the International Physical Activity Questionnaire (IPAQ). In Book of Abstracts 15th International Scientific Conference on Transformation Process in Sport "Sport Performance" (60-61), Podgorica: Montenegrin Sports Academy.
Vukasevic, V., Vukotic, M., \& Masanovic, B. (2018). Comparative study of morphological characteristics and body composition between basketball players from second leagues in Montenegro and Serbia. Journal of Anthropology of Sport and Physical Education, 2(3), 21-25. doi: 10.26773/ jaspe.180704

Vukotic, M. (2010). Nivo morfoloških karakteristika, motoričkih i funkcionalnih sposobnosti sportista različitog sportskog usmjerenja. Neobjavljena magistarska teza. Nikšić: Fakultet za sport i fizičko vaspitanje.

Vukotic, M. (2011). Differences of anthropometric characteristic and moto abilities of different sport orientation. Sport Mont, 9(28-29-30), 112-8.

Vukotic, M. (2018). Comparative analysis of antropmtric indicators of sportisis of different soprts guidance. In Book of Abstracts 15th International Scientific Conference on Transformation Process in Sport "Sport Performance" (7576), Podgorica: Montenegrin Sports Academy.

Vukotic, M., \& Georgiev, G. (2019a). Comparative analysis of anthropometric characteristics between athlets of different orientation, basketball and handball. Journal of Anthropology of Sport and Physical Education, 3(2), 1923. doi: $10.26773 /$ jaspe. 190404

Vukotic, M., \& Georgiev, G. (2019b). Comparative analysis of anthropometric characteristics between athlets of different orientation. Journal of Anthropology of Sport and Physical Education, 3(1), 41-45. doi: 10.26773/ jaspe. 190108

Vukotic, M., Corluka, M., Vasiljević, I., \& Bubanja, M. (2018). Differences in the Morphological Characteristics and Body Composition of Handball Players WHC Levalea in Montenegro and WHC Grude in Bosnia and Herzegovina. Journal of Anthropology of Sport and Physical Education, 2(2), 49-53. doi: 10.26773/jaspe. 180409 